\title{
Role of Phorbol Diesters in In Vitro Murine Megakaryocyte Colony Formation
}

\author{
Michael W. Long, James E. Smolen, Patricia Szczepanski, \\ and Laurence A. Boxer \\ Hematology/Oncology Section, Department of Pediatrics, \\ University of Michigan, Ann Arbor, Michigan 48109
}

bstract. In vitro megakaryocyte differentiation is regulated by two activities: a megakaryocyte colony-stimulating activity (Mk-CSA), which is required for proliferation, and an auxiliary factor, megakaryocyte potentiating activity, which plays a role in later differentiation events. Tumor-promoting phorbol esters alter many cellular differentiation-related events. Thus, it was hypothesized that phorbol esters may bring about megakaryocyte differentiation in vitro. $4 \beta$-Phorbol 12 -myristate 13-acetate (PMA), when co-cultured with a source of Mk-CSA, stimulated a threefold increase in colony numbers. Co-culture of PMA and megakaryocyte potentiator activity did not stimulate colony formation, thus eliminating any action of PMA as an Mk-CSA. The direct effect of PMA on the formation of megakaryocyte colonies was established by $(a)$ the function of PMA as a megakaryocyte potentiator in serum-free experiments, (b) the ability of PMA to stimulate megakaryocyte colony formation using bone marrow cells depleted of populations known to produce potentiating activity, $(c)$ the inability of bone marrow adherent cells previously treated with phorbol, 12,13-dibutyrate (PDBu) to augment megakaryocyte colony formation, and $(d)$ the ability of PMA to induce the growth of immature megakaryocytes into large single megakaryocytes. Structure:activity experiments resulted in equivalent activities for PMA and PDBu, whereas the nontumor promoter phorbol 12,13-diacetate and phorbol itself lacked activity. The observations in this study indicate that phorbol

Dr. Long was a Special Fellow of the Leukemia Society of America during portions of these studies and is the recipient of a New Investigator Award (CA33054); Dr. Boxer is an Established Investigator of the American Heart Association; and Dr. Smolen is Senior Investigator of the Arthritis Foundation.

Received for publication 14 February 1984 and in revised form 2 May 1984.

J. Clin. Invest.

(C) The American Society for Clinical Investigation, Inc.

$0021-9738 / 84 / 11 / 1686 / 07 \quad \$ 1.00$

Volume 74, November 1984, 1686-1692 esters can bring about megakaryocyte differentiation, and during colony formation, can induce effects identical to those brought about by biological sources of megakaryocyte potentiator activity.

\section{Introduction}

The development of megakaryocyte colonies from the murine megakaryocyte progenitor cells (colony-forming unit megakaryocytes, CFU-Mk) ${ }^{1}$ requires the presence of two in vitro regulatory activities: (a) megakaryocyte colony-stimulating activity (Mk-CSA), an obligate factor for the proliferation of the progenitor cell in vitro (1-3), which is produced by a number of tissues, including a murine monomyelocytic leukemia adapted to suspension culture (WEHI-3) (4), and (b) megakaryocyte potentiator activity, produced by bone, bone marrow, spleen, and lung, which increases the DNA content of colonyderived murine megakaryocytes $(5,6)$. Megakaryocyte potentiator activity also directly stimulates murine immature megakaryocytes to differentiate into single mature cells rather than colonies $(7,8)$. This activity, which fails to affect cell proliferation, is necessary for full megakaryocyte development and stimulates an increase in size, and contents of cytoplasm and enzymes, of immature megakaryocytes (8).

In other cell systems, such as the leukemic cell line HL60, or the pheochromocytoma cell line PC12, 4 $\beta$-phorbol 12myristate 13-acetate (PMA) can induce cell differentiation (9, 10). Given the proposed role of tumor-promoting phorbol derivatives in inducing terminal differentiation, it was hypothesized that phorbol esters may bring about megakaryocyte differentiation in vitro. In the following studies we show that PMA can bring about megakaryocyte differentiation and induce effects during megakaryocyte colony formation that are identical to those brought about by the biological sources of the differentiating factor, megakaryocyte potentiator activity.

1. Abbreviations used in this paper: CFU-Mk, colony-forming unit megakaryocyte; CM, conditioned medium; DMSO, dimethyl sulfoxide; FCS, fetal calf serum; Mk-CSA, megakaryocyte colony-stimulating activity; MLuCM, mouse lung conditioned medium; PDA, phorbol diacetate; PDBu, phorbol dibutyrate; PMA, phorbol myristate acetate; TSF, thrombopoietic stimulatory factor; WEHI-3, a murine monomyelocytic cell line. 


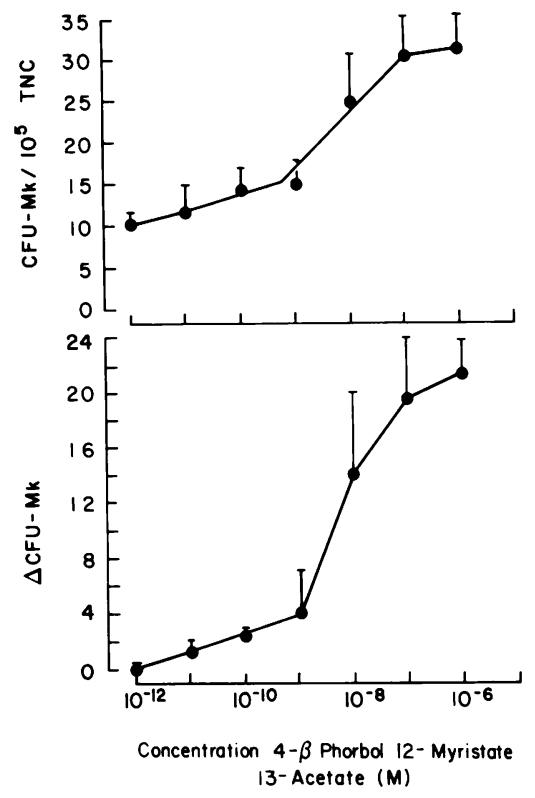

Figure 1. In vitro responsiveness of CFU-Mk to PMA. Progenitor cell assay performed at $10^{5}$ nucleated cells per plate. PMA was cocultured with optimal amounts of WEHI-3 CM $(50 \mu \mathrm{l})$. Lower plot shows the increase in CFU-Mk levels ( $\triangle C F U-M k$ ) over levels stimulated by WEHI-3 CM alone. Values are mean \pm SD from four experiments of three to five replicate plates per concentration per experiment.

\section{Methods}

Megakaryocyte progenitor cell assay. Cells from both femurs of male mice (C57BL/6, Charles River Breeding Laboratories, Inc., Wilmington, MA), 6-10 wk old, were flushed into McCoy's 5A Medium (Gibco Laboratories, Grand Island, NY) and monodispersed. Bone marrow cells were cultured as previously described using conditioned medium (CM) from WEHI-3 and mouse lung CM $(4,5)$. Before plating, the femoral bone marrow cells were generally incubated at $37^{\circ} \mathrm{C}$ for 30 60 min at $\sim 5 \times 10^{6}$ cells $/ \mathrm{ml}$ in McCoy's $5 \mathrm{~A}$ Medium containing $10 \%$ fetal calf serum (FCS). Unfractionated marrow cells were cultured at $10^{5}$ cells $/ \mathrm{ml}$ in $35-\mathrm{mm}$ petri dishes (3001; Falcon Labware, Div. of Beckton-Dickinson \& Co., Oxnard, CA) in modified McCoys' 5A Medium containing $10 \%$ FCS, $0.25 \%$ Bactoagar, and $3 \times 10^{-7} \mathrm{M}$ prostaglandin $\mathrm{E}_{2}$ (Sigma Chemical Co., St. Louis, MO). Prostaglandin $E_{2}$ enhances the assay by stabilizing the colony megakaryocytes and by preferentially lowering the background of granulocyte-macrophage colonies (11). After incubation ( $7 \mathrm{~d}, 37^{\circ} \mathrm{C}, 7 \% \mathrm{CO}_{2}, 100 \%$ humidity), petri dishes were removed from the incubator, dried, and stained in situ for acetylcholinesterase activity (12). Megakaryocyte colonies were counted at a magnification of 40 .

Serum-free experiments were carried out using McCoy's 5A Medium (Gibco Laboratories) using conditions described by Iscove and Melchers (13) as previously modified by Long et al. (8). Optimal levels of bovine serum albumin (BSA, $22 \mathrm{mg} / \mathrm{ml})$, human transferrin $(30 \mu \mathrm{g} / \mathrm{ml})$, both from Sigma Chemical Co., and lecithin $(20 \mu \mathrm{g} / \mathrm{ml}$; Associated Concentrates, Woodside, Long Island, NY) were used in these bioassays. Serum-free WEHI-3 CM and mouse lung conditioned medium $(\mathrm{MLuCM})$ were prepared as described (8) and used in these experiments.
Thus, these experiments were carried out in absolutely serum-free conditions.

In vitro assay for megakaryocyte maturation. Immature megakaryocytes were quantified as described elsewhere (14). Briefly, these cells are morphologically defined as $\leq 18 \mu \mathrm{m}$ diam, having a high nucleus to cytoplasm ratio, and low acetylcholinesterase content. Mature megakaryocytes are cells $>18 \mu \mathrm{m}$ diam, with a low nucleus to cytoplasm ratio, a lobulated nucleus, and a high acetylcholinesterase content. (Further characterization is found in references 7, 8). Immature megakaryocyte development was assayed using in vitro conditions identical to those described above. Immature megakaryocytes were enriched by one of two procedures. Immature megakaryocytes were separated from the bulk of the marrow cells by velocity sedimentation $(7,8)$ or by countercurrent centrifugal elutriation using an elutriator (model J-21M; Beckman Instruments, Inc., Fullerton, CA) (rotor speed $1,500 \mathrm{rpm}$, flow rate $6 \mathrm{ml} / \mathrm{min}$, elution buffer was CATCH media [15] containing $1 \% \mathrm{BSA})$. Under these conditions, $\sim 3 \%$ of the total nucleated cells and $85-95 \%$ of the immature megakaryocytes remained in the elutriation chamber. These cells were then used as input cells for separation by a 1.5 -h sedimentation velocity procedure. This method gave similar but faster separation of immature megakaryocytes than that reported $(7,8)$. Culture conditions were: enriched fractions that contained $10^{2}$ to $10^{3}$ acetylcholinesterase containing immature megakaryocytes were added to each plate in the presence or absence of stimulatory factors. Each plate contained $100 \mu \mathrm{l}$ of pooled fractionated cells, 25-200 $\mu \mathrm{l}$ of stimulatory factor, and $1 \mathrm{ml}$ of serum-free McCoy's 5A Medium containing $0.3 \%$ agar (see above). The plates were incubated for $60 \mathrm{~h}$, stained in situ for acetylcholinesterase $(7,8)$, and examined at a magnification of 100 for the presence of single, mature megakaryocytes $(7,8)$. Controls for $\mathrm{CM}$ experiments were: $(a)$ cultures dried and stained immediately after plating to determine the numbers of input megakaryocytes, and $(b)$ cultures incubated $60 \mathrm{~h}$ without stimuli to determine the numbers of persisting megakaryocytes. The numbers of persisting mature megakaryocytes are $<10$ /plate (8).

Conditioned media. WEHI- 3 cells have been adapted to growth in suspension culture (4). Cells were grown in McCoy's 5A Medium containing $5 \times 10^{-5} \mathrm{M} 2$-mercaptoethanol and $2 \%$ FCS. The medium was harvested every 3-4 $\mathrm{d}$ and concentrated fivefold by ultrafiltration (YM-10; Amicon Corp., Scientific Sys. Div., Danvers, MA). MLuCM was prepared by coarsely cutting murine lungs and suspending 1 lung/ $5 \mathrm{ml}$ of McCoy's 5A Medium. CMs were collected after $3 \mathrm{~d}$ of incubation. Both CMs were also prepared using the described serumfree conditions for serum-free assays. Thrombopoietic stimulatory factor (TSF) was used at a final concentration of $15-25 \mu \mathrm{g} / \mathrm{ml}(7,8)$. The TSF was a generous gift from Dr. T. P. McDonald, University of Tennessee, Knoxville, TN.

Purified megakaryocyte colony-stimulating activity (Mk-CSA). MkCSA was a generous gift from Dr. N. Williams, University of Melbourn, Parkville, Victoria, Australia. Mk-CSA was 30 -fold purified by sizeexclusion and anion-exchange chromatography. Specific activity is 650 $\mu / \mathrm{mg}$ protein calculated according to Iscove et al. (16; N. Williams, personal communication). Such colony-stimulating activity is devoid of megakaryocyte potentiating activity (5). As well, it contained very low levels of granulocyte-macrophage colony-stimulating activity, stimulating only $0.46 \pm 0.5$ granulocyte-macrophage colonies per $10^{5} \mathrm{nu}$ cleated cells/unit plated (data not shown).

Separation by adherence. Bone marrow cells were incubated $\left(3 \times 10^{5}\right.$ cells $\left./ \mathrm{ml}\right)$ in McCoy's 5 A Medium containing 5\% FCS for 1 $h$ at $37^{\circ} \mathrm{C}$ after which the suspension cells were removed and subjected to a second adherence step. The adherent cells were then detached 
using a rubber policeman. Adherent-cell depleted bone marrow was collected after the last incubation and used as a source of target cells in later experiments. Adherent cells from these depletions were collected and set up as feeder layers in McCoy's 5A Medium containing 0.5\% agar.

To test the effect of PMA on bone marrow accessory populations, adherent cells were pretreated at various concentrations $\left(3 \times 10^{5}\right.$, $6 \times 10^{5}$, and $12 \times 10^{5}$ cells $/ \mathrm{ml}$ ) in optimal concentrations of phorbol dibutyrate (PDBu $\left[10^{-6} \mathrm{M}\right]$ ) or an equivalent volume of phosphatebuffered saline (PBS), washed three times and set up in feeder layers, as mentioned above. Overlayers contained $10^{5}$ depleted bone marrow cells in McCoy's 5A Medium containing $0.3 \%$ agar. Additional controls were: $(a)$ feeder layers without cells in the overlayer to ensure that these cells contained no progenitor cells, and $(b)$ the combination of feeder layers and overlayers without stimuli to determine if this combination could support spontaneous colony formation. Neither of these controls resulted in megakaryocyte-colony formation for either the PDBu or PBS pretreatment group.

In a separate experiment, adherent cells $\left(3 \times 10^{5} \mathrm{cell} / \mathrm{ml}\right)$ were coincubated with $10^{-6} \mathrm{M}$ PMA for $3 \mathrm{~d}$ at $37^{\circ} \mathrm{C}$ and tested at $75-200 \mu \mathrm{l} /$ $\mathrm{ml}$ for the ability to augment colony formation. No effect was seen with these CMs.

Separation by velocity sedimentation. Velocity sedimentation was performed at unit gravity according to the method of Miller and Phillips (17). Bone marrow was obtained from 15-20 mice by flushing the femurs with cold $\left(4^{\circ} \mathrm{C}\right)$ PBS. The cells were kept on ice during collection, and separation was carried out at $4^{\circ} \mathrm{C}$. After sedimentation for $2.5 \mathrm{~h}, 35-\mathrm{ml}$ fractions were collected and the cells harvested by centrifugation $(7 \mathrm{~min}$ at $400 \mathrm{~g}$ ). Fractions enriched for immature megakaryocytes (i.e., cells sedimentating at $8-16 \mathrm{~mm} \cdot \mathrm{h}^{-1}$; for details see references 7,8 ) were pooled and plated as described above.

Pooled fractions of cells sedimentating at 3-4 $\mathrm{mm} \cdot \mathrm{h}^{-1}$ were used as target cells in accessing the role of auxiliary cells in the PMA response. Williams has shown that such fractions of cells contain the peak numbers of CFU-Mk, but are devoid of cells capable of elaborating potentiator activity (11).

Phorbol-ester derivatives. Phorbol-ester derivatives were prepared as a stock solution of $10^{-5} \mathrm{M}$ in dimethyl sulfoxide (DMSO) and kept in the dark at $0^{\circ} \mathrm{C}$ until used. Fresh stock solutions were prepared every $3 \mathrm{wk}$. Just before use, a working solution was prepared using McCoy's 5A Medium as a dilutant. Phorbol derivatives tested included: PMA, PDBu, phorbol 12,13-diacetate (PDA), phorbol, all from Sigma Chemical Co., and mezerein (a plant-derived ester of 12-hydroxydaphnetoxin) from L. C. Services Co., Woodburn, MA.

\section{Results}

Substitution of phorbol esters for in vitro megakaryocyte stimulatory activities. Growth of murine CFU-Mk in vitro required the presence of at least two factors for full colony development: WEHI-3 CM and MLuCM. WEHI-3 CM was chosen for its ability to stimulate megakaryocyte progenitor cell proliferation and for its ability to act synergistically with MLuCM, which contains an activity that increases megakaryocyte size and DNA content (3). In these studies, murine CFU-Mk in the presence of MLuCM alone, or WEHI-3 CM alone, grew into 0 and 10 megakaryocytic colonies $/ 10^{5}$ total nucleated cells, respectively. Thus, MLUCM is devoid of detectable levels of Mk-CSA. Co-incubation of bone marrow cells in optimal concentrations of WEHI-3 CM and MLuCM resulted in a threefold increase in the number of megakaryocytic colonies detected (Table I).

When co-cultured with WEHI-3 CM, $10^{-6}$ M PMA was able to replace MLuCM and stimulated a threefold increase in megakaryocyte-colony numbers. Megakaryocyte progenitor cells grown under serum-free conditions showed similar in vitro responsiveness when co-cultured with WEHI-3 CM along with MLuCM or PMA. Finally, PMA $\left(10^{-6} \mathrm{M}\right)$ and PDBu $\left(10^{-6} \mathrm{M}\right)$, but not diluent DMSO, worked synergistically with purified Mk-CSA to produce megakaryocyte colonies (Table I).

PMA was able to act synergistically with Mk-CSA (WEHI$3 \mathrm{CM}$ ) over a range of $10^{-11}$ to $10^{-6} \mathrm{M}$ with optimal concentrations occurring at $10^{-7}$ to $10^{-6} \mathrm{M}$ (Fig. 1). The kinetics of megakaryocyte colony development were identical when stimulated by lung CM or PMA (Fig. 2).

Accessory-cell populations. Williams et al. (18) have shown that bone marrow adherent cells can produce megakaryocyte potentiating activity. Therefore, four approaches were used to address the involvement of this particular cell population: $(a)$ adherent cell depletion, $(b)$ culture of PMA-stimulated adherent cells in feeder layers, $(c)$ preparation of CM from PMA-

Table I. Response of Megakaryocyte Progenitor Cells to CM and Phorbol Esters

\begin{tabular}{lll}
\hline & \multicolumn{2}{l}{$\begin{array}{l}\text { Megakaryocyte progenitor cells } \\
\text { responding per plate }\end{array}$} \\
\cline { 2 - 3 } Stimulus & $\begin{array}{l}\text { Serum-containing } \\
\text { cultures }\end{array}$ & $\begin{array}{l}\text { Serum-free } \\
\text { cultures }\end{array}$ \\
\hline Medium & 0 & 0 \\
MLuCM & $0.9 \pm 0.8$ & $0.4 \pm 0.4$ \\
PMA & 0 & 0 \\
DMSO & 0 & 0 \\
PMA + MLuCM & $1.0 \pm 1.0$ & NT \\
DMSO + MLuCM & 0 & NT \\
WEHI-3 CM & $9.8 \pm 0.6$ & $8.1 \pm 2.8^{*}$ \\
WEHI-3 CM + DMSO & $10.6 \pm 3.9$ & NT \\
WEHI-3 CM + MLuCM & $25.6 \pm 1.4^{*}$ & $28.3 \pm 4.8^{*}$ \\
WEHI-3 CM + PMA & $31.0 \pm 1.5^{*}$ & $26.0 \pm 0.5^{*}$ \\
WEHI-3 CM + PDBu & $29.9 \pm 0.9^{*}$ & $\mathrm{NT}$ \\
Mk-CSA & $3.0 \pm 2.6$ & $\mathrm{NT}$ \\
Mk-CSA + MLuCM & $17.3 \pm 2.8$ & $\mathrm{NT}$ \\
Mc-CSA + PMA & $22.5 \pm 0.7$ & $\mathrm{NT}$ \\
\end{tabular}

Progenitor cell assay performed at $10^{5}$ nucleated bone marrow cells per plate and assayed at day 7 of culture. All serum-containing cultures contained $10-15 \%$ FCS. Values are mean \pm SEM of three to five replicate cultures per experiment for 14 experiments (serum-containing) and three (serum-free) experiments. Mk-CSA data are from a single representative experiment of three to five replicate cultures. PMA, $10^{-7} \mathrm{M}$; Mk-CSA, sp act $650 \mu / \mathrm{mg}$. NT, not tested.

$* P \leq 0.05$ (all statistical testing is by two-tailed $t$ test; comparison is versus WEHI-3 alone). 


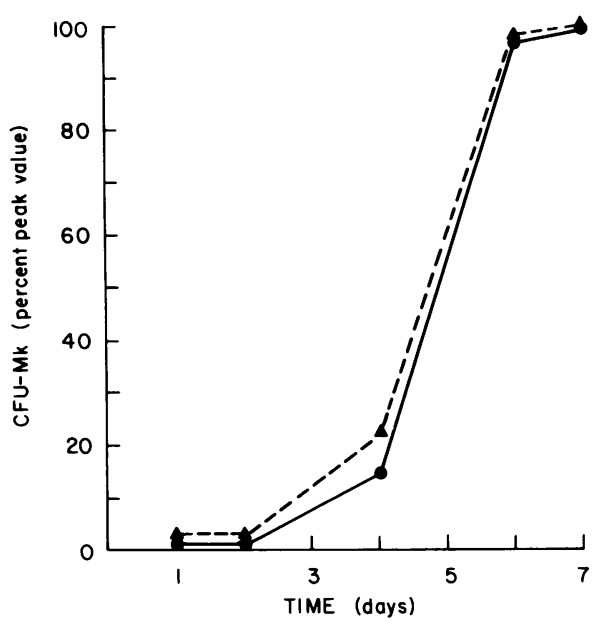

Figure 2. Kinetics of megakaryocyte colony formation stimulated by MLuCM or PMA. Megakaryocytic colonies were assayed at $10^{5}$ nucleated marrow cells per culture containing optimal levels of WEHI-3 CM $(50 \mu \mathrm{l})$ plus MLuCM $(100 \mu \mathrm{l})$ or PMA $\left(10^{-6} \mathrm{M}\right)$. Values are mean of three to five replicate cultures per experiment. A single representative experiment is shown.

stimulated adherent cells, and $(d)$ separation by velocity sedimentation.

Bone marrow cells were exhaustively depleted of adherent cell populations. The resulting depleted bone marrow was tested for response to PMA. The results show that PMA caused a threefold augmentation of megakaryocyte colony formation in nonadherent bone marrow cells (Table II). Conversely, bone marrow adherent cells were collected and stimulated with optimal concentrations of PDBu $\left(10^{-6} \mathrm{M}\right)$.

Feeder layers of these pretreated, washed, adherent cells failed to augment megakaryocyte colony formation (Table II). This was true for all cell concentrations $\left(3-12 \times 10^{5}\right.$ cell $\left./ \mathrm{ml}\right)$ tested. No differences were seen between PMA- and PBStreated adherent cells. The minimal number of colonies observed (Table II) was due to background colonies stimulated by addition of WEHI-3 CM. No background colony growth was seen in the unstimulated controls. Furthermore, CMs from 3-d incubation of PMA and adherent cells failed to augment megakaryocyte colony activity (data not shown).

Progenitor cells sedimenting at $3-4 \mathrm{~mm} \cdot \mathrm{h}^{-1}$ when stimulated with WEHI-3 CM $(50 \mu \mathrm{l})$ and $10^{-6} \mathrm{M}$ PMA were capable of megakaryocyte colony formation. Fractions sedimenting at this velocity range contained $39.1 \pm 11.6 \mathrm{CFU}-\mathrm{Mk}$ per $10^{5}$ nucleated cells compared with $31.0 \pm 1.5$ per $10^{5}$ nucleated cells in unfractionated marrow (values mean $\pm S D$; equivalent colony numbers were observed when stimulated with WEHI$3 \mathrm{CM}$ and $10^{-7} \mathrm{M}$ PMA). The influence of lymphocyte subpopulations was effectively eliminated by separation in velocity sedimentation studies on immature megakaryocytes (see above).

Examination of the structure-activity relationship between various phorbol esters and megakaryocyte colony development.
Table II. Response of Megakaryocyte Progenitor Cells to Adherent-cell Depletion and PDBu Pretreatment of Bone Marrow Adherent Cells

\begin{tabular}{lll} 
& \multicolumn{2}{l}{$\begin{array}{l}\text { Megakaryocyte progenitor cells } \\
\text { responding per plate }\end{array}$} \\
\cline { 2 - 3 } & $\begin{array}{l}\text { Unfractionated } \\
\text { bone marrow }\end{array}$ & $\begin{array}{l}\text { Depleted } \\
\text { bone marrow }\end{array}$ \\
\hline WEHI-3 CM & $10.8 \pm 1.3$ & $15.4 \pm 9.6$ \\
WEHI-3 CM + MLuCM & $29.1 \pm 4.6^{*}$ & $33.7 \pm 1.7^{*}$ \\
WEHI-3 CM + PMA & $26.1 \pm 6.6^{*}$ & $39.9 \pm 0.6^{*}$ \\
WEHI-3 CM + PDBu & $29.9 \pm 2.0^{*}$ & $39.0 \pm 0.1^{*}$ \\
WEHI-3 Cm + & & $8.5 \pm 3.1$ \\
PDBu-treated adherent cells & $\mathrm{NT}$ & $9.0 \pm 3.6$ \\
PBS-treated adherent cells & $\mathrm{NT}$ &
\end{tabular}

Bone marrow adherent cells were pretreated with $\mathrm{PDBu}\left(10^{-7} \mathrm{M}\right)$, washed three times, and set up in feeding layers at various concentrations $\left(3-12 \times 10^{5} / \mathrm{ml}\right)$ in McCoy's $5 \mathrm{~A}$ Medium containing $0.5 \%$ agar. Overlayers contained $10^{5}$ depleted marrow cells in McCoy's $5 \mathrm{~A} \mathrm{Me}$ dium containing $0.3 \%$ agar and WEHI-3 CM $(50 \mu \mathrm{l})$. Values are mean $\pm \mathrm{SD}$ of three experiments of three to five replicate cultures per experiment.

* $P \leq 0.05$. Comparison is versus WEHI-3 CM alone.

$\ddagger$ Values shown are for adherent feeder layers of $3 \times 10^{5}$ cells $/ \mathrm{ml}$. Equivalent values were observed for feeder layers of $6 \times 10^{5} / \mathrm{ml}$ and $12 \times 10^{5} / \mathrm{ml}$.

PMA, PDBu, and mezerein, in the presence of WEHI-3 CM, acted as megakaryocyte potentiators by augmenting megakaryocyte colony formation (Table III). However, the $\mathrm{EC}_{50}$ (i.e., the concentration yielding $50 \%$ of maximal activity) for PMA and $\mathrm{PDBu}$ was $6.6 \times 10^{-9}$ and $7.3 \times 10^{-9} \mathrm{M}$, respectively, whereas the $\mathrm{EC}_{50}$ of mezerein was $8.3 \times 10^{-8} \mathrm{M}$. At concentrations below $10^{-9} \mathrm{M}$, mezerein failed to augment megakaryocyte colony formation. Since mezerein inhibits phorbol binding in other cell systems (15), we tested the ability of

Table III. Structure-Activity Relationship between Various Phorbol Esters and Megakaryocyte-potentiating Ability

\begin{tabular}{lc} 
Phorbol ester & Relative potentiating activity \\
\hline PMA & 100.0 \\
PDBu & 96.5 \\
Mezerein & 57.0 \\
PDA & 0 \\
Phorbol & 0
\end{tabular}

For comparison, the maximum potentiating activity of PMA, when co-cultured with optimal amounts of WEHI-3 CM, is expressed as 100 (representing $31.0 \pm 1.5 \mathrm{CFU}-\mathrm{Mk} / 10^{5} \mathrm{TNC}$ ). All phorbol esters were tested at $10^{-7} \mathrm{M}$. Values are the means of three to five replicate cultures. 
mezerein to block the functional effects of PMA or MLuCM on the murine megakaryocyte progenitor cell. Competition experiments indicated that mezerein $\left(10^{-14}-10^{-8} \mathrm{M}\right)$ could inhibit the effect of $10^{-6} \mathrm{M}$ PMA in a dose-related manner (Fig. 3). Mezerein $\left(10^{-11} \mathrm{M}\right)$ also inhibited the actions of optimal levels of the biologically active MLuCM (Fig. 4).

Effect of PMA on murine immature megakaryocytes. To establish further that PMA could induce megakaryocyte differentiation, we performed the following experiments. Murine immature megakaryocytes (i.e., megakaryocytes $\leq 18 \mu \mathrm{m}$ diam, having low amounts of acetylcholinesterase, and a high nucleus to cytoplasm ratio) respond to biologically active megakaryocyte potentiator activity in vitro by developing into single, mature megakaryocytes $(7,8)$. We observed that PMA could substitute for the biologically active MLuCM in this assay (Table IV). In the presence of PMA, murine immature megakaryocytes were induced to mature into single, large megakaryocytes. The immature megakaryocytes also responded similarly to the presence of TSF, another source of megakaryocyte potentiator activity $(7,8)$.

\section{Discussion}

The tumor-promoting phorbol ester PMA can substitute for one of the in vitro stimulatory activities involved in the regulation of megakaryocytopoiesis-megakaryocyte potentiator activity. The effect of PMA on the formation of megakaryocyte colonies is shown by: the ability of PMA to function as a megakaryocyte potentiator in serum-free conditions; the inability of PMA-induced CMs and PDBu-treated, washed bone

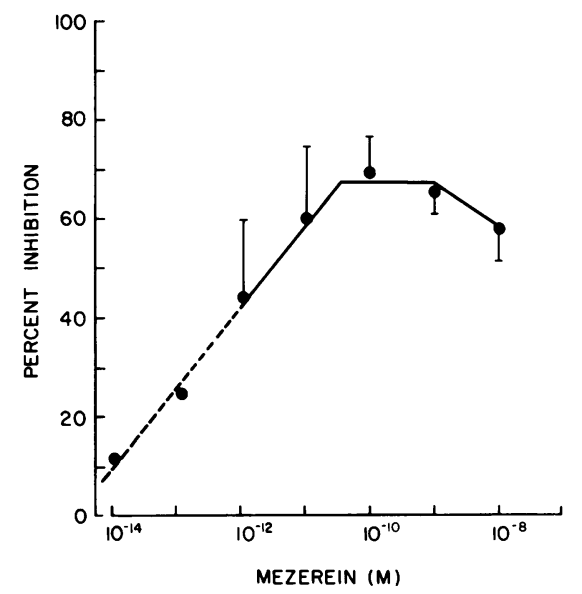

Figure 3. The effect of the concentration of mezerein on megakaryocyte colony-forming cell levels. CFU-Mk assayed in the presence of WEHI-3 CM $(50 \mu \mathrm{l})$ and PMA $\left(10^{-6} \mathrm{M}\right)$. Percent inhibition calculated as $\left[1-\left(\triangle \mathrm{CFU}-\mathrm{Mk}^{\mathrm{a}} / \triangle \mathrm{CFU}-\mathrm{Mk}^{\mathrm{b}}\right)\right] \times 100$, where $\mathrm{a}$ is colonies grown in the presence of WEHI-3 CM, PMA, and mezerein, and $b$ is colonies grown in control cultures containing WEHI-3 CM and PMA. Values are mean \pm SD from two experiments of three to five replicate cultures per point.

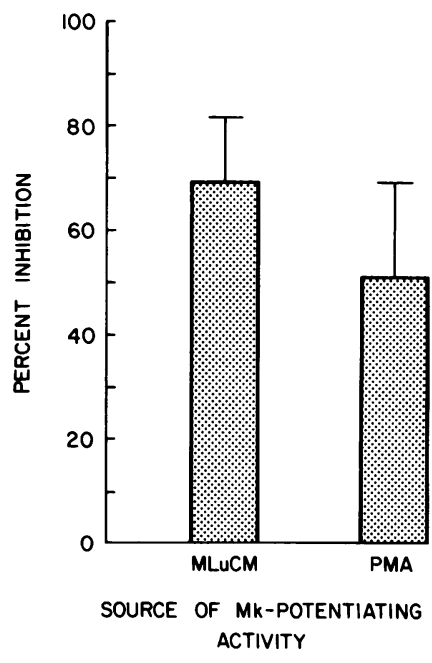

Figure 4. Inhibitory effects of mezerein on PMA and MLuCM-induced augmentation of megakaryocyte colony numbers. Megakaryocyte progenitor cells were assayed as in Fig. 2. Mezerein was tested at $10^{-11} \mathrm{M}$ (final concentration). Percent inhibition was determined as in Fig. 3. Values are mean \pm SD from four experiments of three to five replicate cultures per experiment.

marrow adherent cell feeder layers to augment megakaryocyte colony formation; the ability of adherent-cell depleted bone marrow cells and cells sedimentating at $3-4 \mathrm{~mm} \cdot \mathrm{h}^{-1}$ to respond to PMA; and the serum-free growth of immature megakaryocytes into mature megakaryocytes in the presence of PMA.

PMA functions as a source of megakaryocyte potentiator activity when co-incubated with WEHI-3 CM (a source of Mk-CSA). The concentration of PMA used in these experiments is similar to that reported for the induction of differentiation in the HL60 cell line (9). PMA could not substitute for WEHI$3 \mathrm{CM}$ in stimulating the proliferation of progenitor cells. When incubated with $10^{5}$ bone marrow cells, neither PMA alone, nor the addition of MLuCM to PMA-containing cultures could stimulate colony formation. These observations indicate that PMA cannot function as a megakaryocyte colony-stimulating activity; i.e., it cannot bring about the proliferation and differentiation of progenitor cells into megakaryocytes even when co-cultured with optimal amounts of megakaryocyte potentiator activity (MLuCM).

Table IV. Responsiveness of Single Immature Megakaryocytes to PMA and TSF

\begin{tabular}{lc}
\hline & $\begin{array}{c}\text { Single megakaryocytes responding per } \\
10^{3} \text { immature megakaryocytes plated }\end{array}$ \\
\hline Medium & 0 \\
PMA $10^{-6} \mathrm{M}$ & $103.3 \pm 10.1^{*}$ \\
$10^{-7} \mathrm{M}$ & $64.3 \pm 14.0^{*}$ \\
TSF $(150 \mu \mathrm{g} /$ plate $)$ & $108.2 \pm 16.9^{*}$
\end{tabular}

Immature megakaryocyte assay performed at $2 \times 10^{5}$ fractionated, nucleated cells per plate. Post-sedimentation velocity fractions contained $0.5-1.0 \%$ immature megakaryocytes per plate (for assay details see references 8,9 ). Values are mean \pm SD of two experiments of three to four replicate cultures per experiment.

$* P<0.05$ 
To determine if phorbol esters could stimulate potentiator production by an accessory cell population, experiments using preparations depleted of cells capable of producing megakaryocyte potentiator activity (5) (i.e., bone marrow adherent cells) were performed. Bone marrow adherent-cell preparations were stimulated with $\mathrm{PDBu}$ to see if they could produce potentiator activity in response to phorbol esters. The results of these studies indicate that optimal concentrations of PDBu cannot stimulate bone marrow adherent cell populations (at various cell concentrations) to produce megakaryocyte potentiator activity. Conversely, bone marrow cell preparations devoid of cells capable of producing megakaryocyte potentiator activity retain the ability to respond to PMA. CM prepared by incubating bone marrow adherent cells in optimal $\left(10^{-6}\right.$ M) concentrations of PMA also failed to augment megakaryocyte-colony formation. Williams et al. (18) have shown that cells elaborating megakaryocyte potentiator activity sediment at $5-6.5 \mathrm{~mm} \cdot \mathrm{h}^{-1}$. The observation that PMA can stimulate progenitor cells with a sedimentation velocity of $3-4 \mathrm{~mm} \cdot \mathrm{h}^{-1}$ indicates that the accessory cells in the $5-6.5 \mathrm{~mm} \cdot \mathrm{h}^{-1}$ fractions are not required for the PMA-induced augmentation of colony formation. Moreover, note that all of the megakaryocyte progenitor cell assays are routinely performed in the presence of prostaglandin $E_{2}$, which inhibits the production of biological activities and macrophage colony formation $(19,11)$. Finally, the pooled velocity sedimentation fractions (i.e., cells sedimenting from 8 to $16 \mathrm{~mm} \cdot \mathrm{h}^{-1}$ ) used in the megakaryocyte maturation assay are devoid of lymphocytes which sediment between 3-8 $\mathrm{mm} \cdot \mathrm{h}^{-1}(17)$, thus eliminating lymphocyte subsets as a source of PMA-induced activities. Therefore, the effects of phorbol esters are not mediated by the population of auxiliary cells known to produce megakaryocyte potentiator activity $(5,8,18)$, nor do these effects seem to be mediated by lymphocytes. However, note that the target cell populations used in this study were relatively crude, being either unfractionated bone marrow or cells (immature megakaryocytes) enriched by velocity sedimentation. The use of CM rather than purified biological factors in most of these studies makes direct assessment of the role of Mk-CSA difficult. Given these limitations on the analyses performed, further characterization of the PMA response would be enhanced by using purified populations of stem cells, PMA, and purified Mk-CSA (the latter was used in portions of these studies).

The phorbol ester PMA also stimulates the in vitro maturation of immature megakaryocytes into large, single megakaryocytes. Murine immature megakaryocytes are small acetylcholinesterase-positive cells that are the progeny of the committed megakaryocyte progenitor (CFU-Mk), and have physical-chemical properties intermediate to those of the megakaryocyte progenitor cells and mature megakaryocytes $(7,8)$. They differ from the progenitor cells in that they have lost their ability to proliferate (8). The observation that such immature megakaryocytes respond to PMA substantiates the hypothesis that PMA is working on the megakaryocytic lineage.
Furthermore, it suggests that the responsiveness to phorbol esters extends from the progenitor cell through to at least the earliest morphologically recognizable megakaryocyte, the small acetylcholinesterase-positive cell. However, the $40 \%$ reduction in plating efficiency at $10^{-7} \mathrm{M}$ implies that these cells may not be as sensitive to PMA as the progenitor cells.

Examination of the relationship between the structures of the phorbol esters and the ability of the CFU-Mk to respond to these agents indicates that these cells were stimulated by the tumor promotors PMA and PDBu. The non-tumorpromoting PDA and phorbol itself lacked this potentiating activity. Therefore, the ability of a phorbol ester to induce differentiation in the megakaryocytic lineage may be related to its in vivo actions as a tumor-promoting agent.

Mezerein affects the in vitro growth of megakaryocyte colonies in a biphasic manner. At high concentrations, mezerein has a limited ability to act as a megakaryocyte potentiator. This observation is consistent with mezerein's action as a weak tumor-promoting agent (20). Low concentrations of mezerein can compete with, or inhibit, PMA-induced megakaryocyte colony growth in a dose-dependent manner. Such an observation is consistent with the ability of mezerein to specifically compete with PDBu in other systems (21). Furthermore, mezerein at $10^{-11} \mathrm{M}$ blocked the effects of biologically derived megakaryocyte potentiator activity MLuCM. This suggests that PMA and the biologically derived megakaryocyte potentiator activity either share a common receptor or share a final common mechanism for the induction of differentiation. Recently, a novel protein kinase (protein kinase $C$ ) has been characterized and is thought to play a role in mediating a variety of cellular membrane signals that fail to activate adenylate cyclase in their target tissues (22). Protein kinase C has been shown to be calmodulin insensitive but requires phospholipid and calcium for activity (23). Protein kinase C exists in very high levels in platelets (22), and other observations suggest that protein kinase $C$ may be the PMA receptor (24, 25 ). Thus, protein kinase $C$ may be the cellular site at which PMA and biologically derived megakaryocyte potentiator share common activities.

The observations presented in this study indicate that the phorbol ester PMA can bring about megakaryocyte differentiation and induce effects during megakaryocyte colony formation that are identical to those brought about by biological sources of megakaryocyte potentiator activity. The induction of megakaryocyte development by phorbol esters will allow systematic studies of the cellular mechanisms governing megakaryocyte differentiation. Also, if megakaryocyte differentiation is linked to protein kinase $\mathrm{C}$ activation, then these observations may elucidate general mechanisms of differentiation.

\section{Acknowledgments}

We wish to thank Dr. Neil Williams, University of Melbourn, for his generous gift of Mk-CSA, Dr. Ted McDonald for kindly supplying TSF, and Anne Busch for preparation of the manuscript. 
This work was supported by grants CA 33054-7 from the National Cancer Institute, HL 31568 from the National Heart, Lung, and Blood Institute, AI20065 from the National Institutes of Health, and 83-1169 from The American Heart Association.

\section{References}

1. Metcalf, D., H. R. McDonald, N. Odartchanko, and B. Sordat. 1975. Growth of mouse megakaryocyte colonies in vitro. Proc. Natl. Acad. Sci. USA. 72:1744-1748.

2. Williams, N., and H. Jackson. 1978. Regulation of the proliferation of murine megakaryocyte progenitor cells by cell cycle. Blood. 52:163-169.

3. Burstein, S., J. W. Adamson, D. Thoring, and L. A. Harker. 1979. Characteristics of murine megakaryocyte colonies in vitro. Blood. 54:169-179.

4. Ralph, P., M. A. S. Moore, and K. Nilsson. 1976. Lysosyme synthesis by established human and murine histocyte lymphoma cell lines. J. Exp. Med. 143:1528-1533.

5. Williams, N., R. R. Eger, H. M. Jackson, and D. J. Nelson. 1982. Two factor requirement for murine megakaryocyte colony formation. J. Cell. Physiol. 110:101-104.

6. Williams, N., and H. Jackson. 1982. Kinetic analysis of megakaryocyte numbers and ploidy levels in developing colonies from mouse bone marrow cells. Cell Tissue Kinet. 15:483-494.

7. Long, M. W., N. Williams, and S. Ebbe. 1982. Immature megakaryocytes in the mouse: physical characteristics, cell cycle status, and in vitro responsiveness to thrombopoietic stimulatory factor. Blood. 59:569-575.

8. Long, M. W., N. Williams, and T. P. McDonald. 1982. Immature megakaryocytes in the mouse: in vitro relationship to megakaryocyte progenitor cells and mature megakaryocytes. J. Cell. Physiol. 112:339344.

9. Rovera, J., T. J. O'Brien, and L. Diamond. 1979. Induction of differentiation in human promyelocytic leukemia cells by tumor promoters. Science (Wash. DC). 204:868-870.

10. End, D., N. Tolson, M. Y. Yu, and G. Gurof. 1982. Effects of 12-O-tetradecanoyl phorbol-13-acetate on rat pheochromocytoma (PC 12) cells: interactions with epidermal growth factor and nerve growth factor. J. Cell. Physiol. 111:140-148.

11. Williams, N. 1979. Preferential inhibition of murine macrophage colony forming cells by prostaglandin E. Blood. 53:1089-1094.

12. Williams, N., H. M. Jackson, R. R. Eger, and M. W. Long. 1981. The separate roles of factors in murine megakaryocyte colony formation. In Megakaryocytes In Vitro: Biology and Precursors. B. Evatt, R. Levine, and N. Williams, editors. Elsevier Science Publishing Co., Inc., New York. 59-75.

13. Iscove, N. N., and F. Melchers. 1978. Complete replacement of serum by albumin, transferrin, and soybean lipid in cultures of lypopolysaccaride-reactive B lymphocytes. J. Exp. Med. 147:923-933.

14. Long, M. W., and N. Williams. 1982. Immature megakaryocytes in the mouse: morphology and quantitation by acetylcholinesterase staining. Blood. 58:1032-1039.

15. Levine, R. F., and M. E. Fedorko. 1976. Isolation of intact megakaryocytes from guinea pig femoral marrow. Successful harvest made possible with inhibitors of platelet aggregation; enrichment achieved with a two-step separation technique. J. Cell. Biol. 69:159172.

16. Iscove, N. N., C. A. Roitsch, N. Williams, and L. J. Guilbert. Molecules stimulating early red cell granulocyte, macrophage and megakaryocyte precursors in culture. In Cellular and Molecular Biology of Hematopoietic Stem Cell Differentiation. T. W. Mak, and E. Z. McCulloch, editors. Alan R. Liss, New York. 65-78.

17. Miller, R. G., and R. A. Phillips. 1969. Separation of cells by velocity sedimentation. J. Cell. Physiol. 73:191-202.

18. Williams, N., H. Jackson, P. Ralph, and I. Nakoinz. 1981. Cellular interactions influencing murine marrow megakaryocytes: nature of the potentiator cell in bone marrow. Blood. 57:157-163.

19. Pelus, L. M., H. E. Broxmeyer, J. I. Kurland, and M. A. S. Moore. 1979. Regulation of macrophage and granulocyte proliferation. J. Exp. Med. 150:277-292.

20. Slaga, T. J., S. M. Fischer, K. Nelson, and G. L. Gleason. 1980. Studies on the mechanism of skin tumor promotion: evidence for several stages in promotion. Proc. Natl. Acad. Sci. USA. 77:36593663.

21. Solanki, V., T. J. Slaga, M. Callahan, and E. Huberman. 1981. Down regulation of specific binding of $20-{ }^{3} \mathrm{H}$ phorbol 12,13 -dibutyrate and phorbol ester-induced differentiation of human promyelocytic leukemia cells. Proc. Natl. Acad. Sci. USA. 78:1722-1725.

22. Kawahara, Y., Y. Takai, R. Minakuchi, K. Sano, and Y. Nishizuka. 1980. Possible involvement of $\mathrm{Ca}^{2+}$-activated phospholipiddependent protein kinase and platelet activation. J. Biochem. 88:913916.

23. Wise, B. C., D. B. Glass, C. H. JenChou, R. L. Raynor, N. Katoh, R. C. Schatzman, R. S. Turner, R. F. Kibler, and J. F. Kuo. 1982. Phospholipid-sensitive $\mathrm{Ca}^{2+}$-dependent protein kinase from heart. II. Substrate specificity and inhibition by various agents. J. Biol. Chem. 257:8489-8495.

24. Niedel, J. E., L. J. Kuhn, and G. R. VandenBark. 1983 Phorbol diester receptor co-purifies with protein kinase C. Proc. Natl. Acad. Sci. USA. 80:36-40.

25. Castagna, M., Y. Takai, K. Kaibuchi, K. Sano, U. Kikkawa, and Y. Nishizuka. 1982. Direct activation of calcium-activated, phospholipid-dependent protein kinase by tumor promoting phorbol esters. J. Biol. Chem. 257:7847-7851. 